\title{
The Central Kentucky Prototype: An object-oriented geologic map data model for the National Geologic Map Database
}

\author{
By David R. Soller ${ }^{1}$, Boyan Brodaric ${ }^{2}$, Jordan T. Hastings ${ }^{3}$, Ron Wahl ${ }^{4}$, and \\ Gerald A. Weisenfluh ${ }^{5}$
}

\section{U.S. Geological Survey Open-file Report 02-202}

2002

This report is preliminary and has not been reviewed for conformity with U.S. Geological Survey editorial standards or with the North American Stratigraphic Code. Any use of trade, product, or firm names in this publication is for descriptive purposes only and does not imply endorsement by the U.S. Government.

\section{U.S. Department of the Interior U.S. Geological Survey}

${ }^{1}$ U.S. Geological Survey, 926-A National Center, Reston, VA 20192

${ }^{2}$ Geological Survey of Canada, 615 Booth St., Ottawa, Ontario, CA K1A 0E9

${ }^{3}$ University of California--Santa Barbara, Department of Geography, 3611 Ellison Hall, Santa Barbara, CA 93106

${ }^{4}$ U.S. Geological Survey, Box 25046, Denver Federal Center, Denver, CO 80225

${ }^{5}$ Kentucky Geological Survey, 228 Mining and Minerals Bldg., University of Kentucky, Lexington, KY 40506 


\section{CONTENTS}

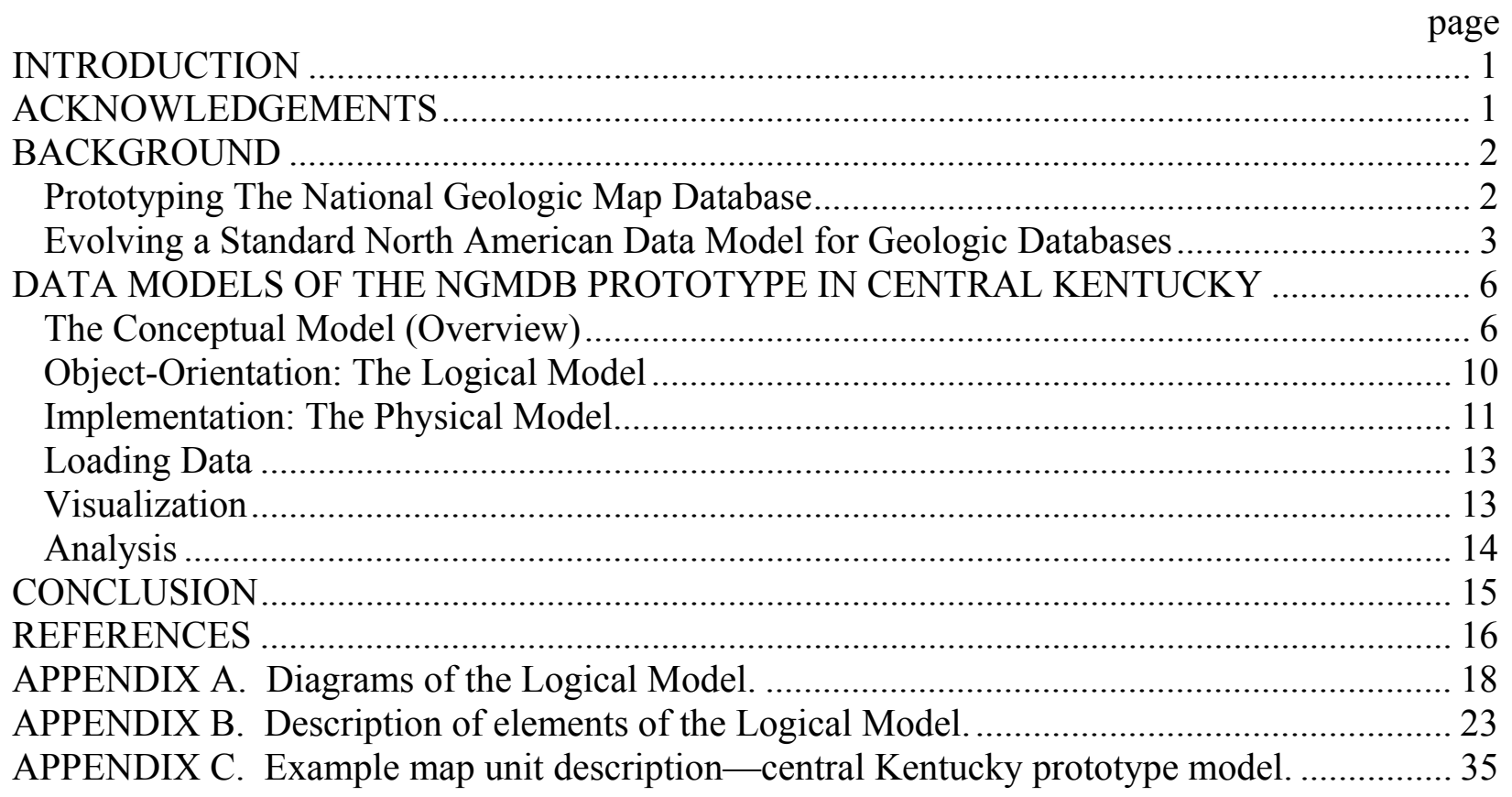




\section{INTRODUCTION}

In the U.S. and Canada, national geologic map databases are being designed and, in prototype form, constructed. These database systems simultaneously address two basic needs: improving the efficiency of routine information handling within an agency, and promoting both traditional and non-traditional uses of geologic information within and outside the agency. In North America, for example, three major systems or initiatives exemplify this approach: 1) the Canadian Geoscience Knowledge Network (CGKN; <http://cgkn.net/>), a cooperative initiative to link the public geoscience data providers in Canada, led by the Geological Survey of Canada (GSC); 2) the U.S. National Geologic Map Database project (NGMDB;

$<$ http://ncgmp.usgs.gov/ngmdbproject/ $>$ ), a Congressionally-mandated database and standardsdevelopment effort based on collaboration between the Association of American State Geologists (AASG) and the U.S. Geological Survey (USGS); and 3) GeoInformatics, a proposed network of U.S. academic geoscience databases (GEON;

$<$ http://www.geoinformaticsnetwork.org/>).

In 1999 and 2000, drawing on experiences from the Canadian and United States initiatives above, the authors undertook to design and build a prototype NGMDB database for central Kentucky, a state well advanced in geological mapping. This report describes the objectoriented data model upon which this prototype was founded, and briefly describes the implementation in the GE-Smallworld database environment. We believe that it is principally through such prototypes that the geoscience community will evolve to a stable set of modeling concepts and implementation approaches that effectively manage digital geologic map information.

At present, however, data modeling of geologic map information is not a mature discipline. Both the data model and the database design presented here are experimental; they were built as prototypes, not formal proposals, and so lack completeness and polish by comparison to some other publicly-accessible database designs for the geosciences. On the other hand, these activities have stimulated additional, advanced data modeling beyond that described here, particularly as reported in Hastings and Brodaric (2001) and Brodaric and Hastings (2002), portions of which are excerpted here for ease of reference. In sum, this is a progress report on geological data modeling in the NGMDB generally, as well as a final report on the prototype for central Kentucky.

\section{ACKNOWLEDGEMENTS}

Each of the five authors brought different expertise and interests to this project, and it is appropriate to identify their contributions. The senior author notes that first-authorship could readily have been justified for each of his coauthors, and he expresses his thanks for their participation in this research. Jerry Weisenfluh contributed to the data model design, prepared the map data for input, and worked closely with the private-sector partners to migrate the data into the database. Ron Wahl contributed to the data model design and administered the database system. Jordan Hastings and Boyan Brodaric led the data model design, which is the core of this 
project; for further information about this work, see their references cited below. David Soller contributed to the data model design and managed the project.

The authors wish to acknowledge the significant interest and expertise provided to this prototype by our private-sector partners, specifically Robert Laudati and Dennis Beck (General Electric Smallworld) and Roger Fredericks and Martin Champion (Techni Graphics Systems). In particular, Mr. Laudati provided the critical technical support that allowed us to translate our data model concepts into a complex and powerful database system. We also thank the Kentucky Geological Survey (KGS) and the U.S. Geological Survey (USGS), specifically James Cobb (KGS) and Patrick Leahy (USGS) for their enthusiastic support and vision for this project.

\section{BACKGROUND}

\section{Prototyping The National Geologic Map Database}

The provisions of the Geologic Mapping Act of 1992 and its reauthorizations in 1997 and 1999 (PL106-148) require the U.S. Geological Survey (USGS) to design and build a National Geologic Map Database (NGMDB), with the assistance of the state geological surveys (via the AASG) and other entities participating in the National Cooperative Geologic Mapping Program $(<$ http://ncgmp.usgs.gov/>). In consultation with the principal architects of the NGMDB legislation, a general plan for the project's implementation and evolution was proposed (Soller and Berg, 1995). A progress report is provided annually (e.g., Soller and Berg, 2001).

The NGMDB plan identifies three complementary phases to the project. Because many organizations produce and distribute geologic maps, and because the majority of these are not yet in digital form, it was essential at the project's outset to identify and catalog all extant geologic maps for the United States, in either paper or digital format. This first phase, which at this writing we consider to be mature, has produced a Web-accessible geologic map catalog ( $<$ http://ngmsvr.wr.usgs.gov/ngmdb/ngm_catalog.ora.html $>$ ) which enables users to search for maps for their area and/or theme of interest. This map catalog presently is supported by two additional databases developed under the NGMDB project: 1) GEOLEX, a searchable geologic names lexicon; and 2) Geologic Mapping in Progress, which provides information on current mapping projects. As new mapping projects conclude, their map products are entered into the map catalog.

The second phase of the NGMDB project focuses on public access to geologic maps in digital form, meaning both as raster graphics and as vector GIS datasets. The latter goal, in particular, requires the development of standards for encoding digital geologic map contents, as well as guidelines for their documentation and use. This is an extremely important activity that requires a high level of interaction with all stakeholders to ensure that the evolving standards and guidelines are useful, necessary, and will be widely adopted.

The ultimate goal of the NGMDB, in its third and final phase, is to create an online database containing geological and geoscientific information that can be Web-queried, downloaded for analysis, customized for display and/or plotting, etc. as the user desires. Although derived to a 
large extent from geologic maps, this database is intended to be accessible as a coherent, seamless whole, incorporating both map and non-map content. Further, the database is to be updated as new geologic maps are published so that it becomes a dynamic, "living" database. General concepts and a report of progress on NGMDB's "phase three" are provided in Soller et al. (2001).

Possible architectures and implementations for phase three are being evaluated through a series of prototypes. Each prototype is designed to prove key technical concepts, forge relations and agreements among the collaborators (principally, the nation's geological surveys), and also begin amassing representative collections of geologic map information. In early 1999, the basic requirements for a first prototype geologic map database were articulated and tested using some newly-developed digital data for the Greater Yellowstone Area (GYA) of Wyoming and Montana (Wahl et al., 2000). The GYA prototype was presented for discussion at the Geological Society of America (GSA) Annual Meeting, in October, 1999. That prototype was wellreceived, and planning began for a second prototype with a more complex set of tasks.

The second prototype evolved in late 1999 through 2000, via a series of meetings among the USGS, the Kentucky Geological Survey (KGS), and representatives of various state constituency groups, universities, and vendors. The original intent of this follow-on prototype was to test applicability of the GYA research results in a production geologic mapping environment at the state level. Significantly, Kentucky has:

- A large amount of detailed (1:24,000-scale) map data available, which has been standardized and edge-matched into 1:100,000-scale quadrangles,

- An enthusiastic interest in designing a prototype and implementing a standard data model, and

- A proven record of statewide economic benefits from the geologic mapping.

In fact, the NGMDB prototype for central Kentucky focused almost exclusively on the development and implementation of an advanced data model (as suggested by the GYA work) in GE-Smallworld (GESW) a commercial object-relational GIS/database management system (DBMS). In mid-2001, this prototype became available for public comment; results are described in Soller et al. (2001).

\section{Evolving a Standard North American Data Model for Geologic Databases}

The Kentucky prototype benefits from half a decade of work on a suitable database structure, or data model, for geologic map databases. This work began in 1996 at a meeting in Saint Louis, Missouri, sponsored by the NGMDB project and the AASG. That meeting was convened to organize "working groups" to develop standards relevant to the NGMDB and to the participating agencies. A broad cross-section of geologic interests was represented, including the AASG, USGS, and GSC.

From the Saint Louis meeting, a Data Model Working Group (DMWG) was formed (see $<$ http://ncgmp.usgs.gov/ngmdbproject/standards/datamodel/datamodelWG.html $>$ for annual reports and related information). In its first year, the DMWG produced three iterations of a digital geologic 
map data model, all of which were discarded with lessons learned (see Raines and others, 1997). After two years, in June 1998, a fourth data model iterate, known simply as "v4.2", was formally presented to its AASG, GSC, and USGS sponsors at an invitational workshop in Denver, Colorado. After some further minor modification, a "v4.3" draft (Johnson and others, 1998) was informally released on the web for public comment (initially at the NGMDB site, now available at $<$ http://geology.usgs.gov/dm/ $>$ ). This data model was predicated on relational database implementation. With release of that model, the DMWG had completed its task.

In early 1999, the North American Data Model Steering Committee (NADMSC) was established to administer future data model developments and implementations, with a Web forum established at $<$ http://geology.usgs.gov/dm/>. The NADMSC adopted v4.3 as the provisional standard, referring to it informally as the North American Data Model, or NADM. Collaterally, since its inception NADMSC has monitored and coordinated among groups implementing NADM.

Many attempts to implement NADM in real systems (viz., commercial GIS and/or DBMS) have required some change in the underlying model concepts. Nonetheless, the state geological surveys and several projects in the USGS have successfully adapted ideas from v4.3 to their internal needs, and/or have proposed adding to v4.3 aspects of their internal systems (for example, (Stanford and others, 1998; Davis, 2001; Richard and Orr, 2001). Through several Canadian projects, principally CordLink $<$ http://cordlink.gsc.nrcan.gc.ca/cordlink/> and HydroLink $<$ http://www.cgq-qgc.ca/hydrolink/>, the GSC has evolved a substantially different system, commonly referred to as "v5.x".

Within the NGMDB project, too, the GYA prototype initially attempted to implement NADM. However, GYA was implemented as yet another ad hoc, and in this case object-oriented, variant. Coincidentally, an object-oriented design had been sketched concurrently with v4.2 but never implemented. For the NGMDB Kentucky prototype, following the Yellowstone experience, it was determined to reassess this alternative modeling approach.

In late summer 2000, two of the present authors (Brodaric and Hastings), who had been active contributors throughout the above-mentioned modeling and prototyping process, met to coalesce the existing v4.3 and v5.x data models into a more evolved structure. This new data model reconceptualizes previous efforts in two important ways:

- It is a meta-(data) model, a progenitor for numerous particular data models, of which the existing assortment may be considered examples.

- It is object-oriented, explicitly designed in, and intended for implementation via, that emerging software paradigm.

A meta-model is, by definition, a model of models; in the present context, a master model for a (reasonably) wide variety of geologic map models. The meta-model's generality is achieved by recognizing the similarities (vs. the differences) of individual models, necessarily with some loss of specificity. Object-orientation is particularly useful for this sort of abstraction, as it focuses on building "class hierarchies", in which similarities (vs. differences) can be summarized. The central tenet of this work is that a sufficiently capable meta-model can not only subsume past variations, but also presume future ones, flexibly and robustly. Meta-modeling and object- 
orientation are the means to the essential goal of enhanced intercommunication and interoperability between data models.

Data models typically occur at three levels of representation in the database construction process (Date, 1999): conceptual, logical, and physical. At the conceptual level, essential concepts from the domain under consideration are represented in a technology-neutral formalism. The logical level then translates the conceptual model into a specific technology, viz., entity-relational or object-oriented DBMS. Finally, the physical model adapts the logical model to a particular hardware and software environment, e.g., a particular version of DBMS. In practice, database implementations also may manifest one or more external models, which are user-specific subsets of the total logical data model that simplify it for particular purposes: e.g., a comprehensive geologic map database might be subset for applications in engineering, paleontology, etc.

In their recent work with meta-modeling, Hastings and Brodaric (2001), Brodaric and Hastings (2002), and Brodaric and Gahegan (2002) primarily address the conceptual level, although logical considerations also are evident since their design is explicitly object-oriented.

Implementation of aspects of these designs for the Kentucky prototype has also resulted in a physical model. 


\section{DATA MODELS OF THE NGMDB PROTOTYPE IN CENTRAL KENTUCKY}

\section{The Conceptual Model (Overview)}

A scientific (versus cartographic) view of a geologic map strongly considers the meaning (as well as the appearance) of a map, including the spatial relations between its symbols, and the connections of the symbols to information not shown on the map. Semiotics, the study of signs (Noth, 1990), provides a useful framework for representing this viewpoint. In cartographic semiotics the meaning of a map symbol derives from the relationship held between the symbol, the concept being symbolized (per some interpreting agent), and the object being referred to (MacEachren, 1995). This semiotic triangle (i.e., symbol, concept, occurrence), abstracted to geologic maps, is sketched in part of Figure 1; a fourth vertex (description), turning the triangle into a diamond, is shown below these in the Figure. This "diamond diagram" represents the essential structure of the meta-model.

- Symbol: refers to the (carto)graphic entities in the visual display, ultimately building up to maps, charts, tables, etc. Almost universally, symbols permit only a partial representation of the underlying geologic information, encoded in relation to concepts and occurrences. Independent treatment of symbols clearly separates them from specific software packages, viz., GIS, and also enables purely cartographic behavior related to scale dependencies, symbol overlap, etc., separate from the geologic information they seek to represent.

- Concept: refers to the abstract entities by which geologic information is summarized: e.g., "Dakota formation", "granite", "fault", "intrudes", etc. Specific geologic vocabulary is used to clarify and formalize concepts, which typically manifest in hierarchical category systems, e.g., taxonomies, applicable to occurrences (below) and relationships held between them.

- Occurrence: refers to the tangible entities by which geologic information is identified and recognized, i.e., geologic (and general geospatial) features in the environment and their relationships in space, time, and otherwise. Each identifiable occurrence is an instance of exactly one concept; being tangible, it optionally possesses a spatial description, its geometry.

- Description: refers to the characterizations (either numeric or textual, but not geometric) assigned to a symbol, concept or occurrence; these encode the preponderance of knowledge about a symbol, concept or occurrence, beyond its pure existence. Over time, descriptions per se also tend to become embedded in the recognition of concepts and occurrences.

Frequently in the natural sciences, concepts are really prototypical descriptions, reflecting either 1) some average summary of occurrences (with some occurrences more typical than others), or 2) an ideal state (Solomon, 2000). An example of the summary case is a generic characterization of mapped units in the legend; an example of the ideal state occurs when an individual occurrence comes to define a concept, viz., a type locality. Thus, descriptions of basic concepts and related occurrences may be very similar, or very different, depending on their similarity to the summary or ideal prototype. Accommodating this fact, the meta-model possesses a common 
data store for descriptions, as illustrated in Figure 2, which allows concept and occurrence descriptions to share, or vary, either structure and content as required. Further extensibility can be achieved by specializing descriptions into subtypes, as needed, also illustrated in Figure 2.

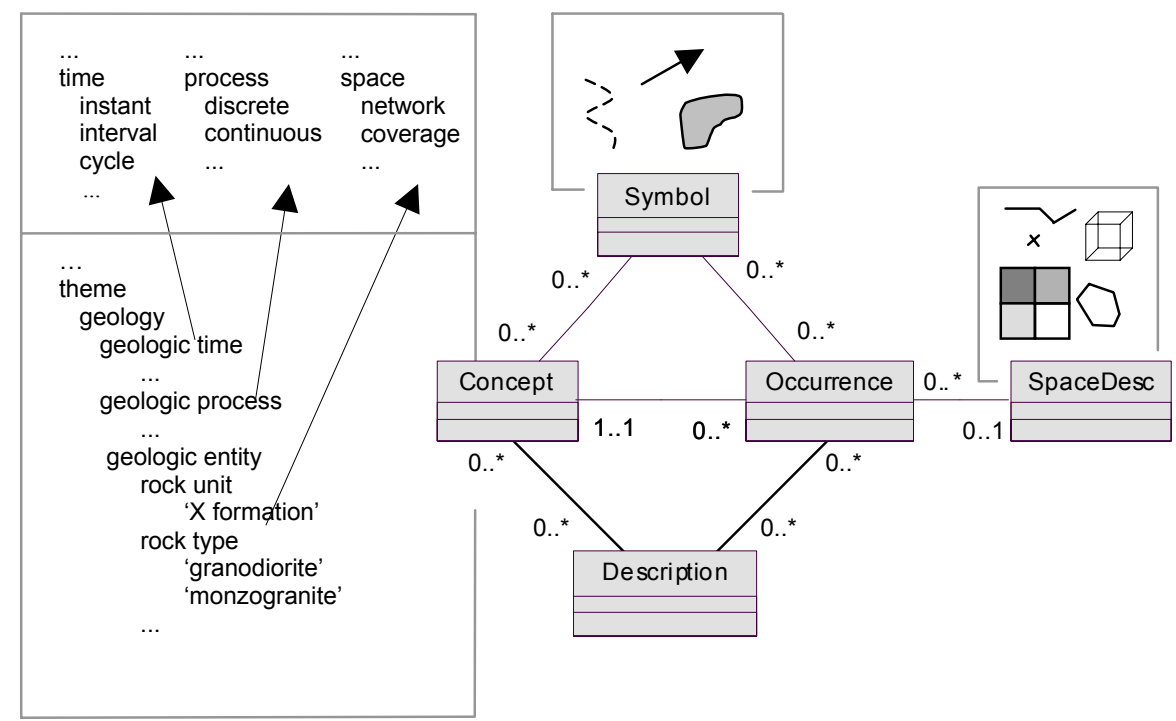

Figure 1. The semiotic triangle (symbol, concept, occurrence), augmented to a diamond (with description), in simplified UML notation (Rumbaugh et al. 1999), abbreviated for reasons of clarity and space. Insets show example instances of spatial geometries (right), symbols (top) and concepts (left); indents and arrows denote concept specialization.

The development of a geologic map is a sophisticated process that involves reasoning about categories of mapped information (concepts) according to both existing scientific theories and new observations (occurrences). Concepts and occurrences may be obtained in parallel and are mutually affective: evidence from many occurrences guides evolution of concepts, while established concepts are being continuously retested on each new occurrence. Hypotheses and interpretations also play vital roles in the process. Both the evidence for, and the summary of, this thinking are recorded in descriptions, which attach equally to concepts and occurrences, as shown in Figures 1 and 2.

As field geologists map an area, they progressively develop conceptual models that describe the general concepts and rules that govern the occurrence of geologic features. The conceptual model can encompass more specific models, e.g., for petrography, stratigraphy, genesis, etc. (Heyn and others, 2000). Also, the conceptual model is often tied to an occurrence model, one that describes the distribution of geologic and other occurrences jointly in space and time, as well as any explanatory inferences. In practical terms, the conceptual model is typically sketched in the map legend (and its associated text and figures), whereas occurrences appear in the map itself. For a map to be coherent, its conceptual and occurrence models must be interconsistent. 


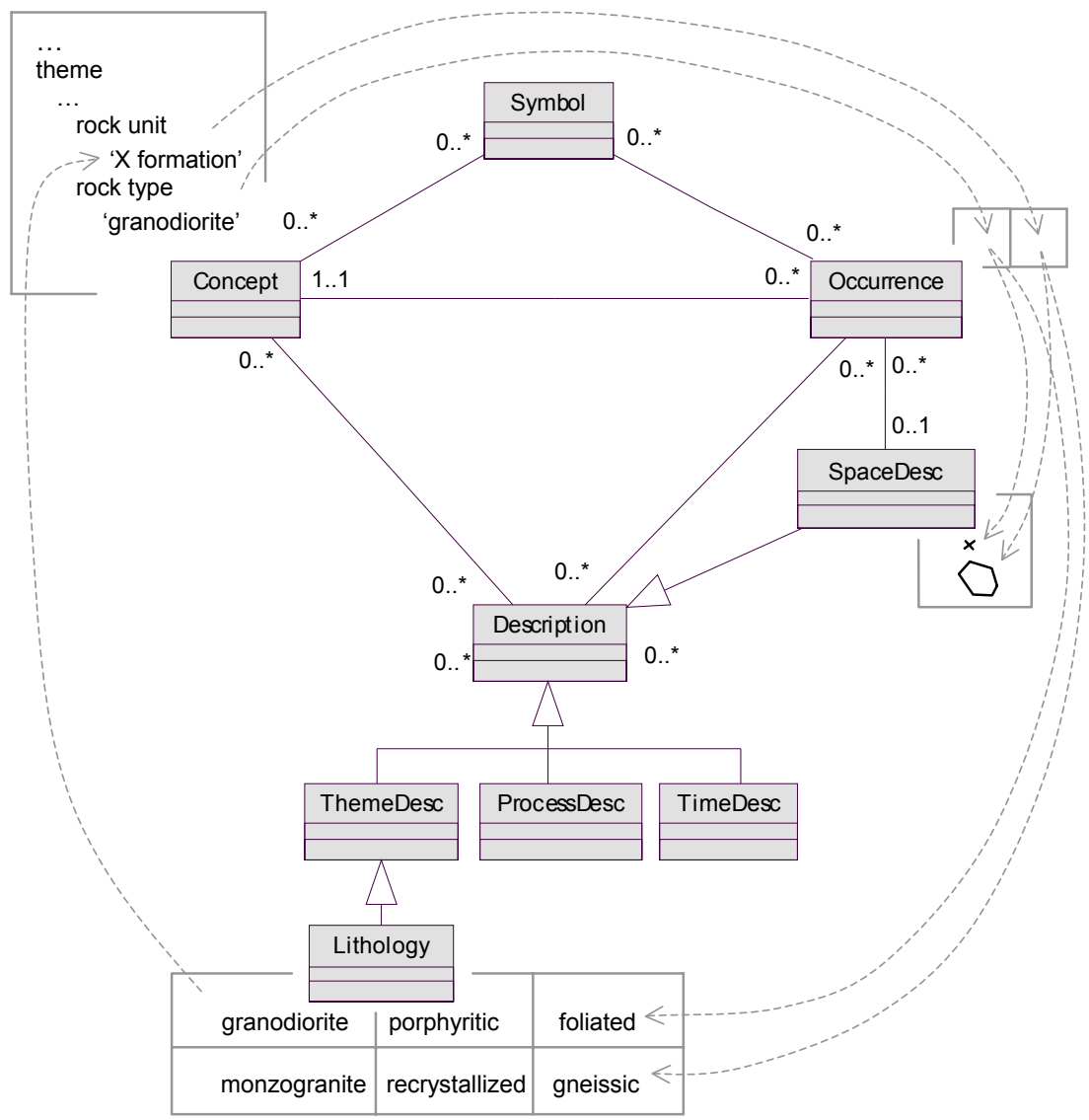

Figure 2. Amplification of the essential meta-model structure (diamond diagram). Insets show example instances of concepts (left) and occurrences (right) with related spatial geometries (right) and thematic descriptions (bottom). Dashed lines illustrate concepts evolving from occurrences.

In information science, conceptual models are formally known as ontologies (Guarino, 1998); these are commonly manifested as vocabularies, taxonomies, or classification schemes, such as those for geologic time ("Precambrian"), rock units ("Dakota formation"), rock types ("granite"), minerals, etc. By extension, we consider occurrence models as epistemologies, formalizing how we know and evaluate geologic realities (Raper, 1999). The two models are fundamentally linked: an ontology provides a set of concepts and logic for how occurrences can be arranged; and the epistemology - the set of geologic features recognizable in the real world and on the map, as well as their causal and process explanations and development histories - demonstrates the validity of the concepts and related logic. Again, a map that "works" clearly expresses this linkage.

To be useful, a meta-model must be implemented in a real system, i.e., in a geologic map database, as described in following sections. From the database geologic maps can, of course, be regenerated. How does the meta-model terminology apply to these geologic maps? A geologic map can be considered to be a conceptual model (ontology and theory) expressed as a legend (a symbolized conceptual model, devoid of occurrences that in turn exemplifies an occurrence 
model (epistemology) for the region of interest. The map shows objects from one or more geospatial models (i.e., GIS layers), and/or utilizes descriptions from some aspatial models (i.e., attribute databases). Applying an alternate legend to the same set of occurrences effectively generates a re-conceptualized (derivative) visualization for the area. This construction fulfills the initial premise that maps are tightly interwoven arrangements of symbolized concepts and symbolized occurrences, as sketched in Figure 3, where a map is denoted by the MapView object.

The general knowledge structure described above emphasizes the relationships among and between symbols, concepts, occurrences, and descriptions. Specific knowledge representations can be achieved by grouping these primitives into arrangements called models: symbolic (i.e., cartographic) models for symbol sets, geospatial models for geometric data sets, and descriptive models for descriptions themselves. For example, a palette is a model of symbols denoting a particular symbol library or agency-approved cartographic standard. Similarly, a geospatial model is a summary of the organization and relations (geometry and topology) that denote a dataset/layer in a GIS. Finally, a geologic map together with its legend is a fixed combination of these basic types. 


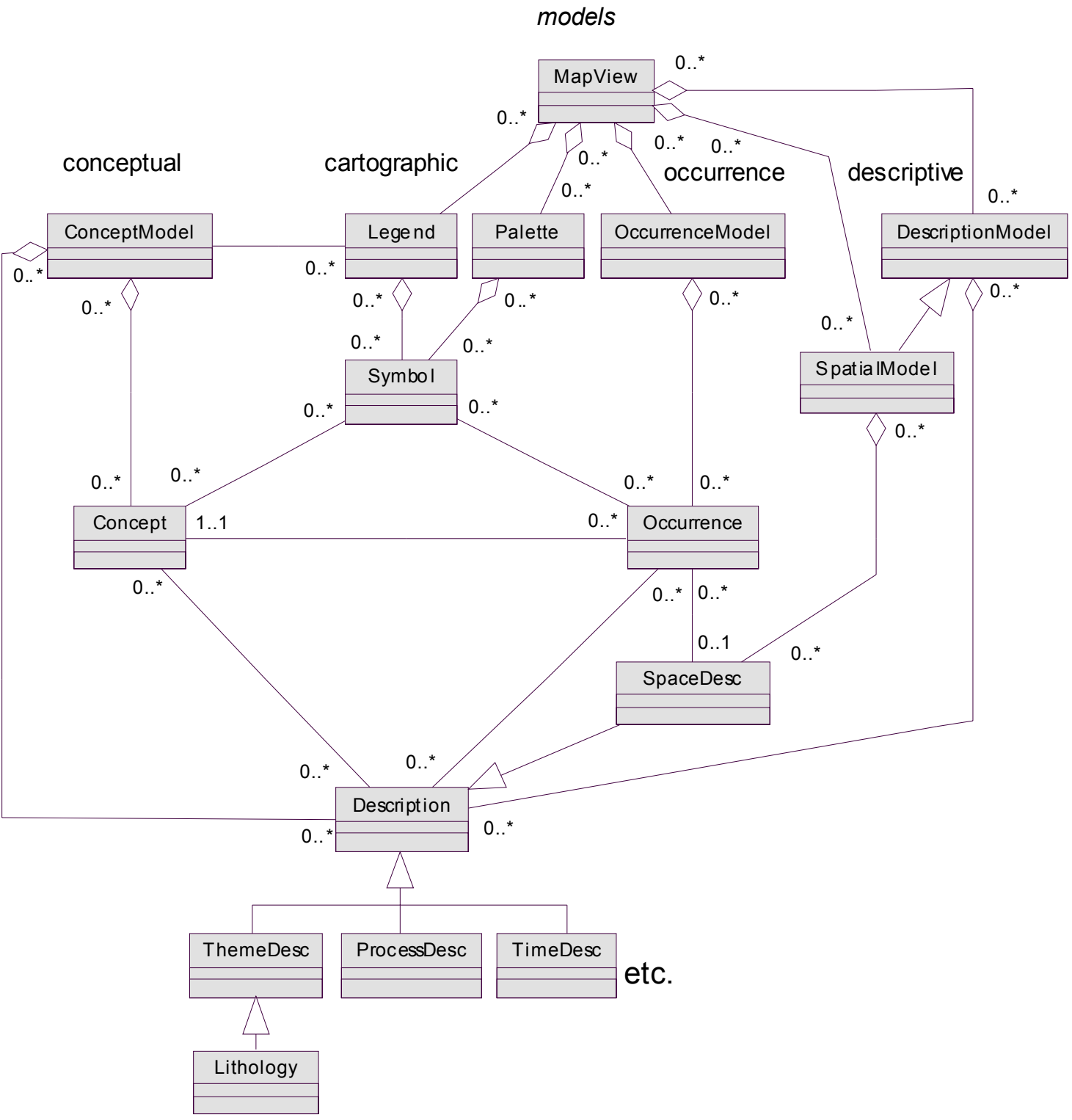

Figure 3. The definition of a geologic map in the meta-model, abbreviated for reasons of clarity and space. See Appendices for details.

\section{Object-Orientation: The Logical Model}

The complete logical, object-oriented model for this prototype comprises seven principal classes of objects, including concepts (17 subclasses), descriptions (13 subclasses) and symbols (2 basic subclasses), as well as their aggregate models and supporting metadata. Occurrences and their aggregate occurrence models are, of course, dynamic according to map content. Details are documented in the Appendices. 
It should be noted that several aspects of the logical model remain in need of refinement:

- The description objects comprising standard attributes (i.e., "pick lists") are present only in preliminary form (in many cases directly from v.4.3) and require significant development.

- The symbolic objects also require elaboration to achieve cartographic sophistication, as well as development to better serve multi-map databases.

- The subclassing of concepts in the logical diagrams is not consistent with pure objectorientation.

\section{Implementation: The Physical Model}

This prototype was implemented in General Electric's "Smallworld" GIS (GESW), operating on a Windows 2000 Server computer system. GESW is object-relational software. Its physical data model is created in a CASE tool, which ensures that all objects have the commonly required characteristics of identity, encapsulation, inheritance (multiple) and polymorphism, and substitutability. Communication among objects is by inter-object messaging. However, instances of all objects are stored in a relational database with the necessary methods, ancillary tables, and other program segments hidden from view. The relational data structures and required object manipulations are customized in a proprietary language called "MAGIK", based loosely on SmallTalk (Lewis 1995). Consultants from General Electric Net Services and TechniGraphics Systems, Inc. (Ft Collins, CO) wrote several hundred lines of MAGIK code during the Kentucky prototype implementation process.

Two immediate benefits of the GESW implementation were:

- Semantic fit: The new object-oriented data model was realized nearly verbatim in the GESW system (compare Figure 4 and Figure 2). Because the model and the GIS share object-oriented semantics, none of the usual conflicts between formal design and actual implementation of software occurred. On the contrary, the GIS anticipated the application in various ways.

- Technical functionality: The new model took full advantage of technical capabilities in the GESW system, and stretched them a bit. Both concepts and occurrences were outfitted with behaviors (processes) that optimized their display at various scales. Some concepts and descriptors were specialized into various sub-classes "tuned" to the Kentucky data, for example, coal seams (Deposits) and structure contours (Surfaces).

In addition, several features specific to the GESW software proved beneficial:

- Adaptive symbology: Mappable objects were assigned different cartographic symbols according to map scale, creating the appearance that the map became more detailed as the user zoomed closer.

- Dynamic topology: Topologic relations were maintained automatically during even the most complex analytic activities, including those that resulted in the creation of new occurrences on the map.

- External data interface: Map-related data in external databases, specifically drillholes (maintained by KGS) and formal geologic names information (maintained by USGS) were easily integrated using HTTP and/or ODBC protocols. 
- Internet access: Both the GESW application and its underlying database were accessible by a standard Web browser, using Citrix Metaframe; this had the added benefit of protecting security in USGS networks.

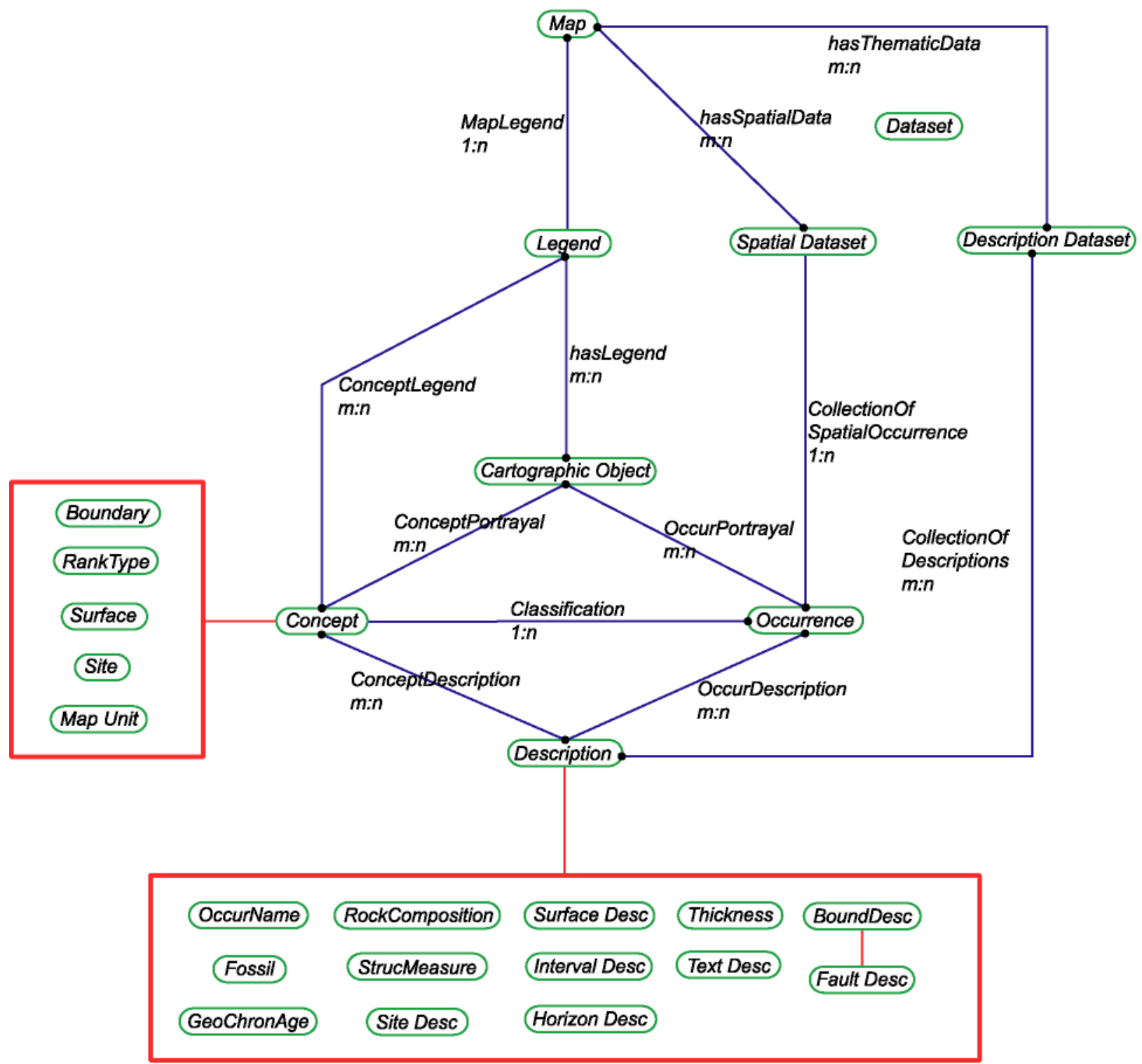

Figure 4. The core physical model in GESW. This was only a partial implementation of the logical model shown in Appendix A. Some descriptions were inserted into the model as placeholders for future development (namely, GeoChronAge, and StrucMeasure). The implemented concepts and descriptions are shown in the red boxes. The red line connecting "BoundDesc" and "FaultDesc" demonstrates that a relation can occur among descriptive elements (here, a fault also can be a boundary between map units). The relations between data model entities (e.g., "Map", "Description") can be one-to-many (denoted textually as " $1: n$ " and graphically as a line with a round termination at the "many" box) or many-to-many (denoted textually as "m:n" and graphically as a line with a round terminations at both ends). 


\section{Loading Data}

Data for this prototype were supplied by the KGS in ESRI "shapefile" and MS Excel spreadsheet formats. Populating the data model with map information involved disaggregating this "legacy" feature-based structure - thematically distinct layers of geospatial features each with spatial, symbol, and descriptive attributes, as well as external database links - and reorganizing it into conceptual, occurrence, symbol and descriptive models. At the same time descriptive information scattered amongst disparate data sources, such as externally held stratigraphic lexicons, were reunified and interrelated (see Table 1). Concepts embedded in feature attribute values, theme labels, and external sources were collected and organized into conceptual models for rock units, rock types, and minerals; similarly, the symbol attributes of features were collected and organized into a single cartographic palette. The spatial attributes of features from all maps each became distinct but topologically-related GESW native spatial objects; the various descriptive attributes became free-standing descriptions; and the external database references, which inherited GESW's external data access methods, became active links. This transformation resulted in a dataset that was on the one hand more normalized (i.e., concept, symbol, and attribute descriptions were not replicated for features), and on the other hand more integrated (much scattered data were unified and directly embedded).

Table 1. Relations among rock units (geologic unit name and unit relations), in the GESW database.

\begin{tabular}{lcc} 
Stearns coal zone & Contains & Beaver Creek coal horizon \\
Stearns coal zone & Contains & Stearns No. 2 coal horizon \\
Breathitt Group & Contains & Princess Formation \\
Breathitt Group & Contains & Grundy Formation \\
Breathitt Group & Contains & Alvy Creek Formation \\
Grundy Formation & Contains & Corbin Sandstone Member \\
Alvy Creek Form. & Contains & Livingston Conglomerate \\
$\ldots$ & $\ldots$ & $\ldots$ \\
\hline
\end{tabular}

\section{Visualization}

The meta-model above provides sufficient structure for performing map-based visualization from a geospatial database. We tested this structure under three visualization scenarios: 1) direct display of a stored map; 2) display based on reclassification of existing spatial objects; and 3) dynamic symbolization of concepts and occurrences at multiple scales.

- Display: A mapview $\rightarrow$ display method (a GESW procedure programmed in MAGIK) was used to display a map's occurrence model from the database (Figure 5, left). This method also activated various pieces of information, so that, for example, clicking on a spatial object returned only those concepts, descriptions, and symbols belonging to the mapview. 

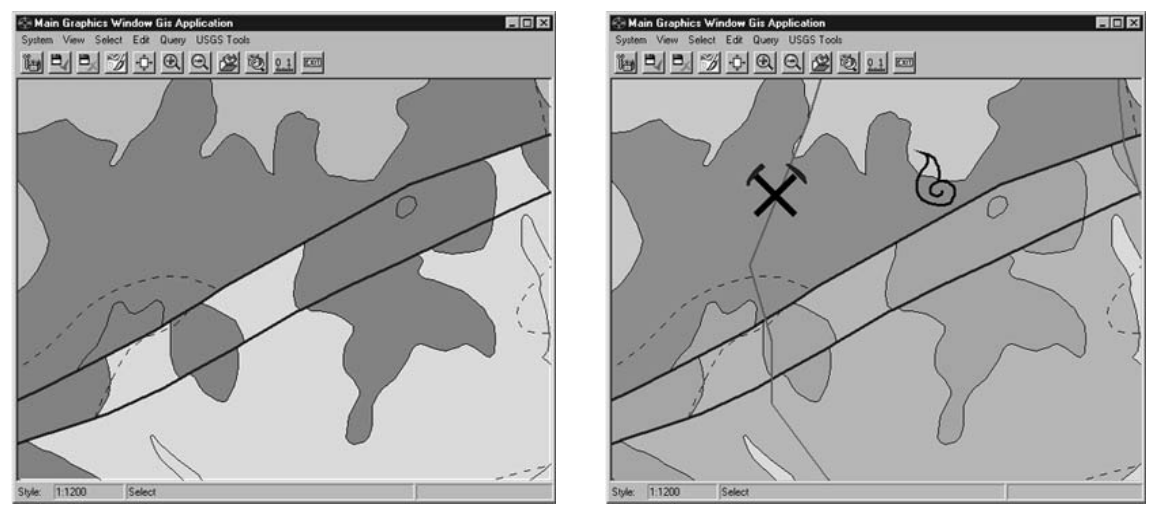

Figure 5. Display and generalization of maps using Kentucky prototype test data. Rock unit occurrences (left) are dynamically reclassified into their dominant rock types (right); also symbolized (right), without using a standard pallette, are a mine and a fossil locality.

- Reclassification: A mapview $\rightarrow$ reclass method was used to re-conceptualize a map, i.e., to derive a new map view from the one currently displayed. In this method, concepts and spatial objects from the current map view were retained, whereas additional occurrences and symbols were created or activated. Figure 5 shows rock unit occurrences (left) and a derived map view displaying their dominant rock types (right) dynamically derived from associated rock unit concept descriptions.

- Symbolization: An occurrence $\rightarrow$ display method was used to dynamically display an occurrence. This allowed for both default and custom cartographic representations, permitting different representations to be shown depending on display scale. For example, in Figure 5, as a user zooms into an area, more specific information about paleontologic features is shown (right).

\section{Analysis}

The fundamental purpose of this prototype was to develop in GESW software an implementation of an object-oriented data model. This software provides a robust analytical capability and, to a limited extent, we decided to explore it in preparation for the next prototype. Therefore, for demonstration purposes, a simple network analysis was performed. Dominant rock type occurrences were evaluated in terms of their inherent susceptibility to contamination and their occurrence downstream from pollutant discharges. To perform this analysis, a powerful function of GESW was invoked - the capability to both display and query external databases held by the user.

For this analysis, external databases of potential pollution sources, streams, and elevation were identified by the user and translated on the fly by GESW for display with the geologic map information. Typical GIS operations were performed on external databases to identify pollution sources adjacent to streams, compute from the elevation data the downstream direction, and then, in conjunction with the geologic map database, identify geologic units that are susceptible to contamination and are intersected by streams, downvalley from pollution sources. The resulting 
map highlighted several potential contamination sources, and more importantly, demonstrated the significant potential for integrating geologic information with a wide variety of thematic information in external or user databases. This capability significantly enhances the potential for non-geologists to use geologic map information in their analyses and decisionmaking. Further, the analysis demonstrates that the meta-model can interact with common external data sources in typical GIS environments where objects are associated primarily in terms of spatial relations, with little regard for the knowledge and highly semantic relations inherent in geoscience and maintained by the meta-model.

\section{CONCLUSION}

Owing largely to geology's rich conceptual and symbolic traditions, geologic map information is complex and poses many challenges for digital representation. Nonetheless, development of widely applicable and broadly accepted standards for digital geologic map information is crucial to improving the overall usability of such information, both within the geosciences and beyond.

This prototype demonstrates both an evolution of the NADM into a fully object-oriented design and an implementation of that design that appears fundamental to the long-term NGMDB effort. However, this prototype was only an isolated test, a first proof-of-concept, for object orientation as applied to digital geologic map information. Guidelines need to be developed - debated and decided within the geologic community - regarding how best to represent a broad spectrum of geologic phenomena within the model's core structure. Concurrently, the meta-model itself needs to be enhanced with more sophisticated behaviors regarding geologic classification, description, and inheritance; for example constraints/defaults on lithostratigraphic relationships and intra-rock-unit compositions are required.

Much time and effort was expended in transliterating the Kentucky maps from a traditional georelational form (ESRI's ArcInfo coverages) into an object-oriented form (GESW-internal objectrelational database). A flexible, data-driven and/or parameterized software utility for this chore is clearly needed, given the disparate formats for map information in the fifty state geological surveys, and also within the USGS.

The "scalability" of GESW's performance with increasing data volumes also requires testing, since the amount of digital geologic map information that must eventually be captured is enormous.

Finally, presuming that various GIS infrastructures and geologic databases will be retained in the various geologic mapping agencies, the potential use of the GESW system as a "mediator", to achieve interoperability among them, needs to be explored. This mediation will become particularly important as NGMDB progresses in its third phase, providing a distributed on-line database of geologic map information. 


\section{REFERENCES}

Brodaric, Boyan, and Hastings, Jordan, 2002, An object model for geologic map information, 쓰: D. Richardson and P. van Oosterom (eds.), Advances in Spatial Data Handling: $10^{\text {th }}$ International Symposium on Spatial Data Handling, Ottawa, Canada, July 8-12, 2002, p. $55-68$.

Brodaric, Boyan, and Gahegan, Mark, 2002, Distinguishing instances and evidence of geographical concepts for geospatial database design, in M. Egenhofer and D. Mark (eds.), Geographic Information Science-2nd Int'l Conference: GIScience 2002, LNCS 2478, Springer, Berlin.

Date, C.J., 1999, An introduction to database systems, Volume 1, $7^{\text {th }}$ ed.: Addison-Wesley, New York. 975 p.

Davis, A.M., 2001, Will a standard data model work for Washington, DC area geologic geospatial data?, in D.R. Soller, ed., Digital Mapping Techniques '01 -- Workshop Proceedings: U.S. Geological Survey Open-File Report 01-223, p. 225-229, $<$ http://pubs.usgs.gov/of/2001/of01223/davis.html>.

Guarino, N., 1998, Formal Ontology in Information Systems, in Guarino N. (ed.), Formal Ontology in Information Systems: Proceedings of FOIS'98, Trento, Italy, June 6-8, 1998, IOS Press, Amsterdam, p. 3-15.

Heyn, G., Kuebler, S., Richter, B., Skala, W., and Voisard, A., 2000, The geohyp project: representing knowledge in geologic hypermaps: GEO-Informationssysteme, v. 13, no.13, p. 24-28.

Hastings, Jordan, and Brodaric, Boyan, 2001, Evolution of an object-oriented, NADM-based data model prototype for the USGS national geologic map database project: Proceedings, International Association of Mathematical Geology Annual Meeting, Cancun, Mexico, Sept. 9-12, <http://www.kgs.ukans.edu/Conferences/IAMG/Sessions/I/brodaric.html>.

Johnson, B.R., Brodaric, Boyan, Raines, G.L., Hastings, J.T., and Wahl, Ron, 1999, Digital Geological Map Data Model v4.3: informal report, 69 p., $<$ http://geology.usgs.gov/dm/model/Model43a.pdf $>$.

Lewis, Simon, 1995, The Art and Science of Smalltalk: Prentice-Hall, 250 p.

MacEachren, A. M., 1995, How Maps Work: Representation, Visualization and Design: Guilford Press, New York.

Noth, W., 1990, Handbook of Semiotics: Indiana University Press, Bloomington. 
Raines, G.L., Brodaric, Boyan, and Johnson, B.R., 1997, Progress Report -- Digital Geologic Map Data Model, in D.R. Soller, ed., Proceedings of a Workshop on Digital Mapping Techniques -- Methods for Geologic Map Data Capture, Management, and Publication: U.S. Geological Survey Open-File Report 97-269, p. 43-46, $<$ http://pubs.usgs.gov/openfile/of97269/raines.html>.

Raper, J., 1999, Spatial representation: the scientist's perspective, in P.A. Longley, M.F. Goodchild, D.J. Maquire, and D.W. Rhind (eds.), Geographical Information Systems: Principles and Technical Issues, $2^{\text {nd }}$ ed.: Wiley, New York, p. 61-70.

Richard, S.M., and Orr, T.R., 2001, Data structure for the Arizona Geological Survey Geologic Information System: Basic geologic map data, in D.R. Soller, ed., Digital Mapping Techniques '01 -- Workshop Proceedings: U.S. Geological Survey Open-File Report 01223, p. 167-188, <http://pubs.usgs.gov/of/2001/of01223/richard2.html>.

Rumbaugh, J., Jacobson, I., Booch, G., 1999, The unified modeling language reference manual: Addison-Wesley, Reading, MA.

Soller, D.R., and Berg, T.M., 2001, The National Geologic Map Database: A Progress Report, 트 D.R. Soller, ed., Digital Mapping Techniques ‘01 -- Workshop Proceedings: U.S. Geological Survey Open-File Report 01-223, p. 51-57, $<$ http://pubs.usgs.gov/of/2001/of01223/soller1.html>.

Soller, D.R., Wahl, Ron, Weisenfluh, Jerry, Brodaric, Boyan, Hastings, Jordan, Laudati, Robert, and Fredericks, Roger, 2001, Progress report on the National Geologic Map Database, Phase 3 - an Online Database of Map Information, in D.R. Soller, ed., Digital Mapping Techniques '01 -- Workshop Proceedings: U.S. Geological Survey Open-File Report 01223, p. 71-78, <http://pubs.usgs.gov/of/2001/of01223/soller2.html>.

Soller, D.R., and Berg, T.M., 1995, Developing the National Geologic Map Database: Geotimes, v. 40 , no. 6 , pp. $16-18$.

Solomon, K. O., Medin, D. L., and Lynch, E., 1999, Concepts do more than categorize: Trends in Cognitive Sciences, v.3, no. 3, p. 99-104.

Stanford, L.R., Othberg, K.L., Lewis, R.S., and Breckenridge, R.M., 1999, A Digital Geologic Map Data Model Designed for GIS Users, in D.R. Soller, ed., Digital Mapping Techniques '99 -- Workshop Proceedings: U.S. Geological Survey Open-File Report 99386, p. 169, <http://pubs.usgs.gov/openfile/of99386/stanford.html>.

Wahl, R.R., Soller, D.R., and Yeldell, Steven, 2000, Prototype Implementation of the NADMSC Draft Standard Data Model, Greater Yellowstone Area, in D.R. Soller, ed., Digital Mapping Techniques '00 -- Workshop Proceedings: U.S. Geological Survey Open-File Report 00-325, p. 57-63, <http://pubs.usgs.gov/openfile/of00325/wahl.html>. 


\section{APPENDIX A. Diagrams of the Logical Model.}

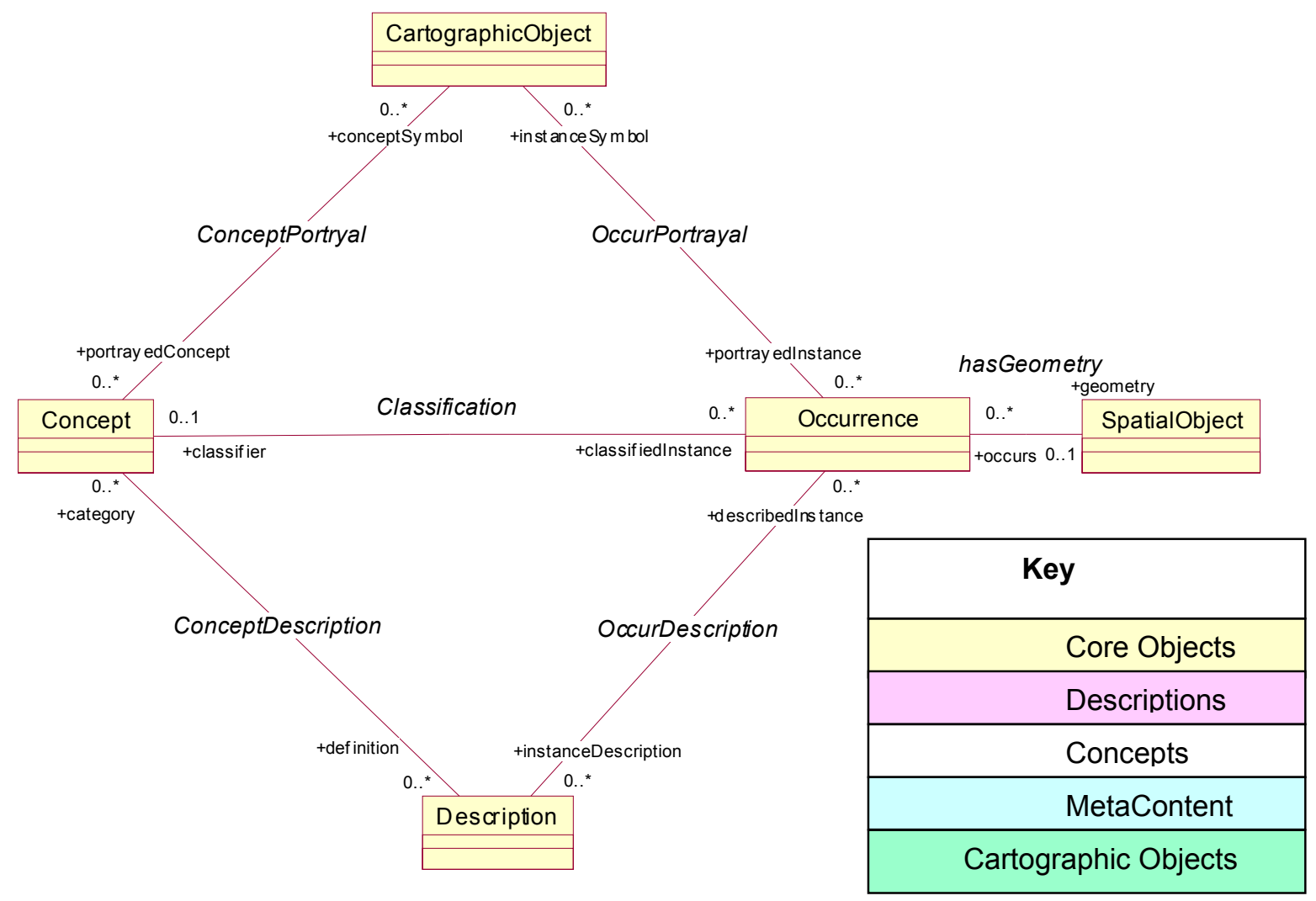

Figure A. Core objects of the meta-model: concept, occurrence, description, cartographic object and spatial object. 


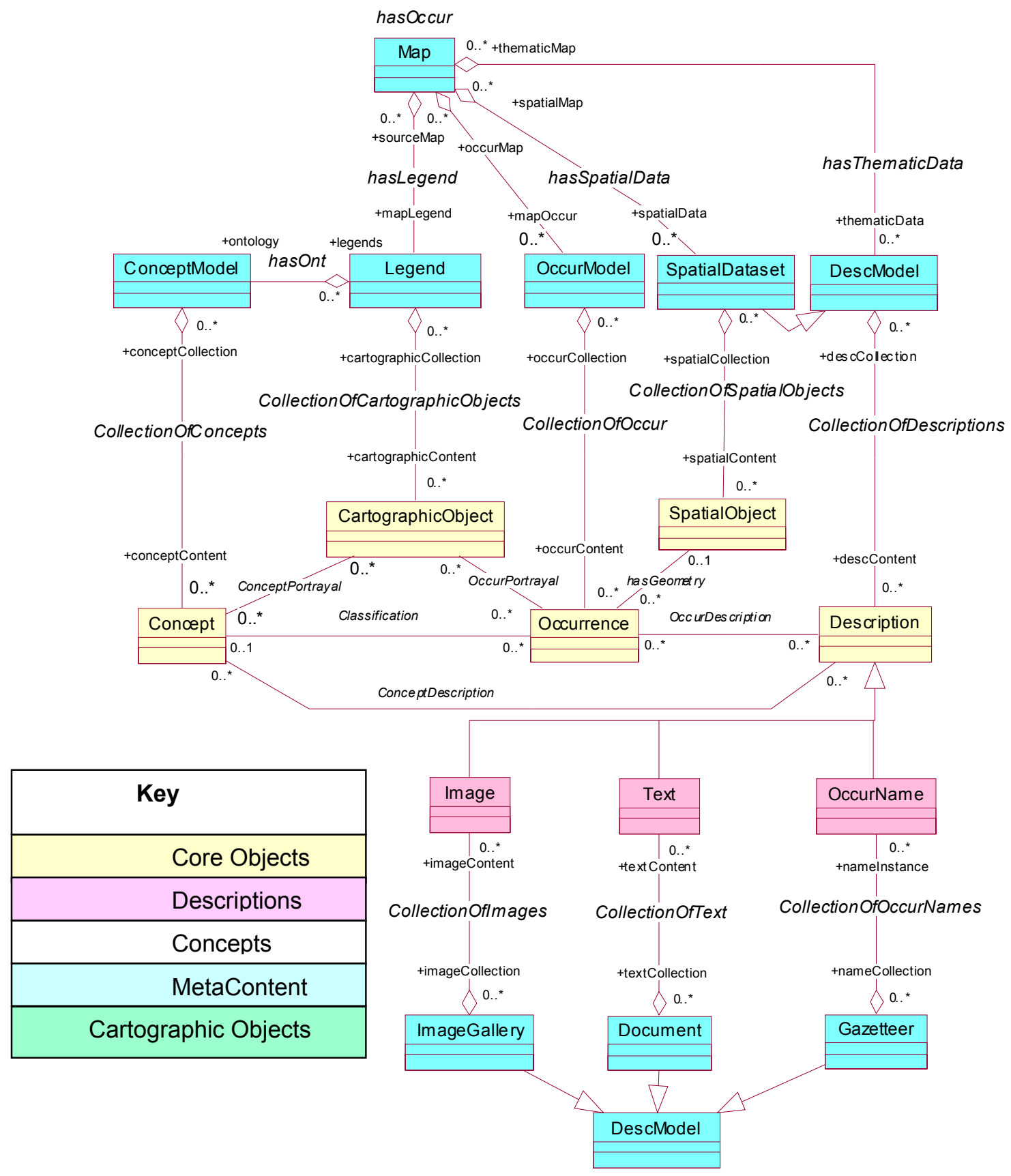

Figure B. Additional details of the meta-model, including the definition of a map. 
The Central KY Prototype: An object-oriented geologic map data model for the National Geologic Map Database

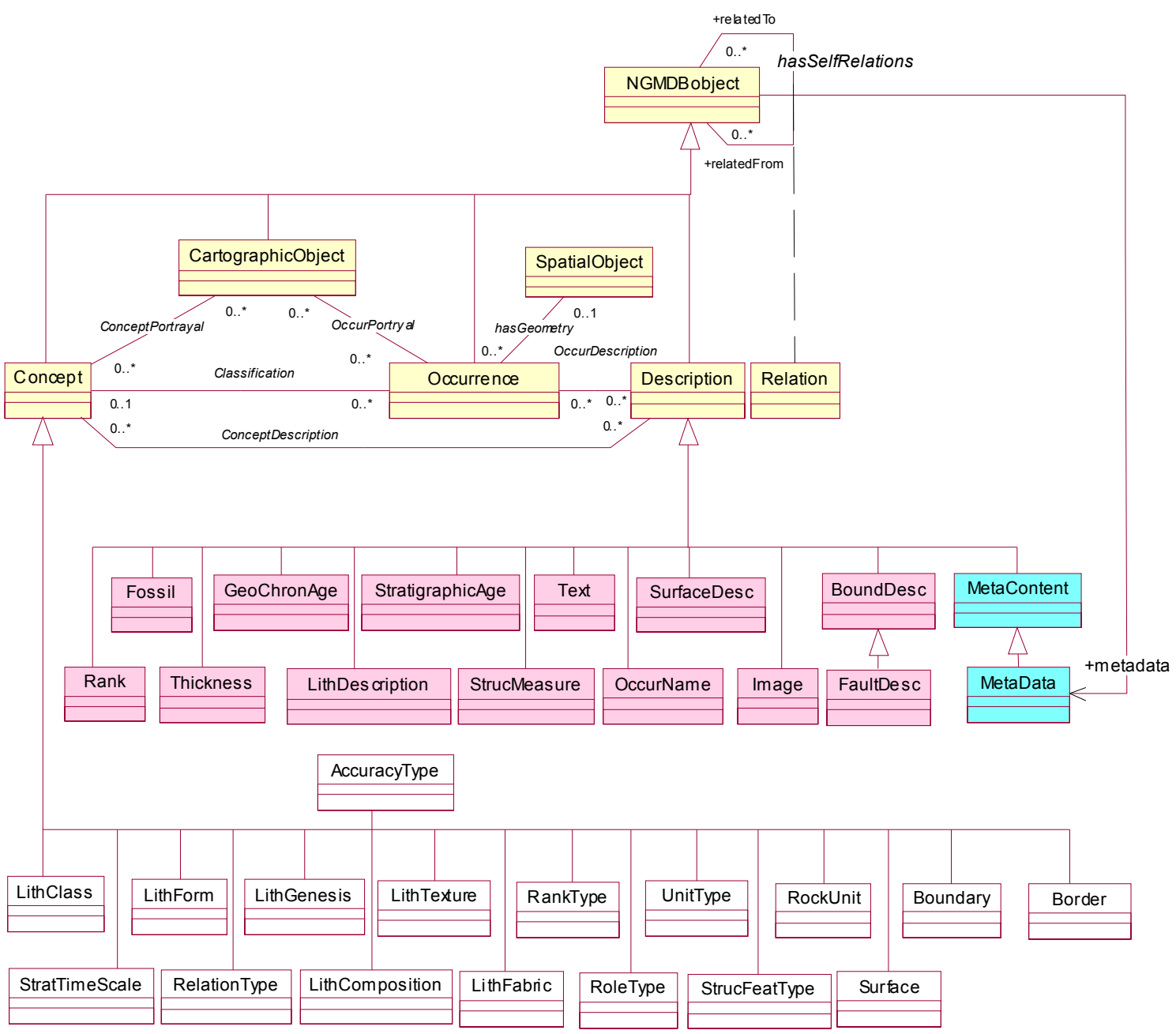

Figure C. Descriptions and concepts.

\begin{tabular}{|c|}
\hline Key \\
\hline Core Objects \\
\hline Descriptions \\
\hline Concepts \\
\hline MetaContent \\
\hline Cartographic Objects \\
\hline
\end{tabular}




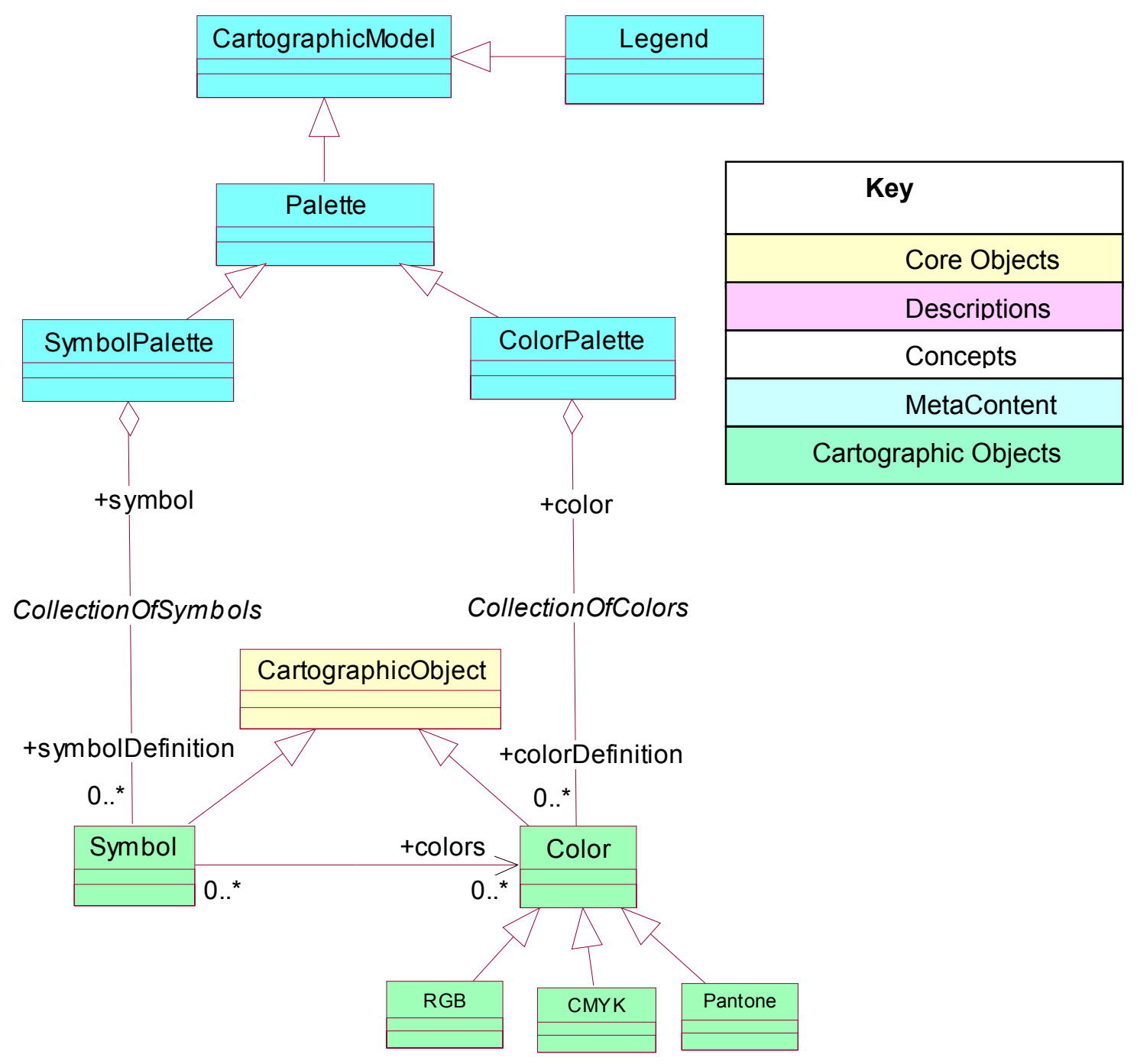

Figure D. Cartographic models, including legend and palettes. 


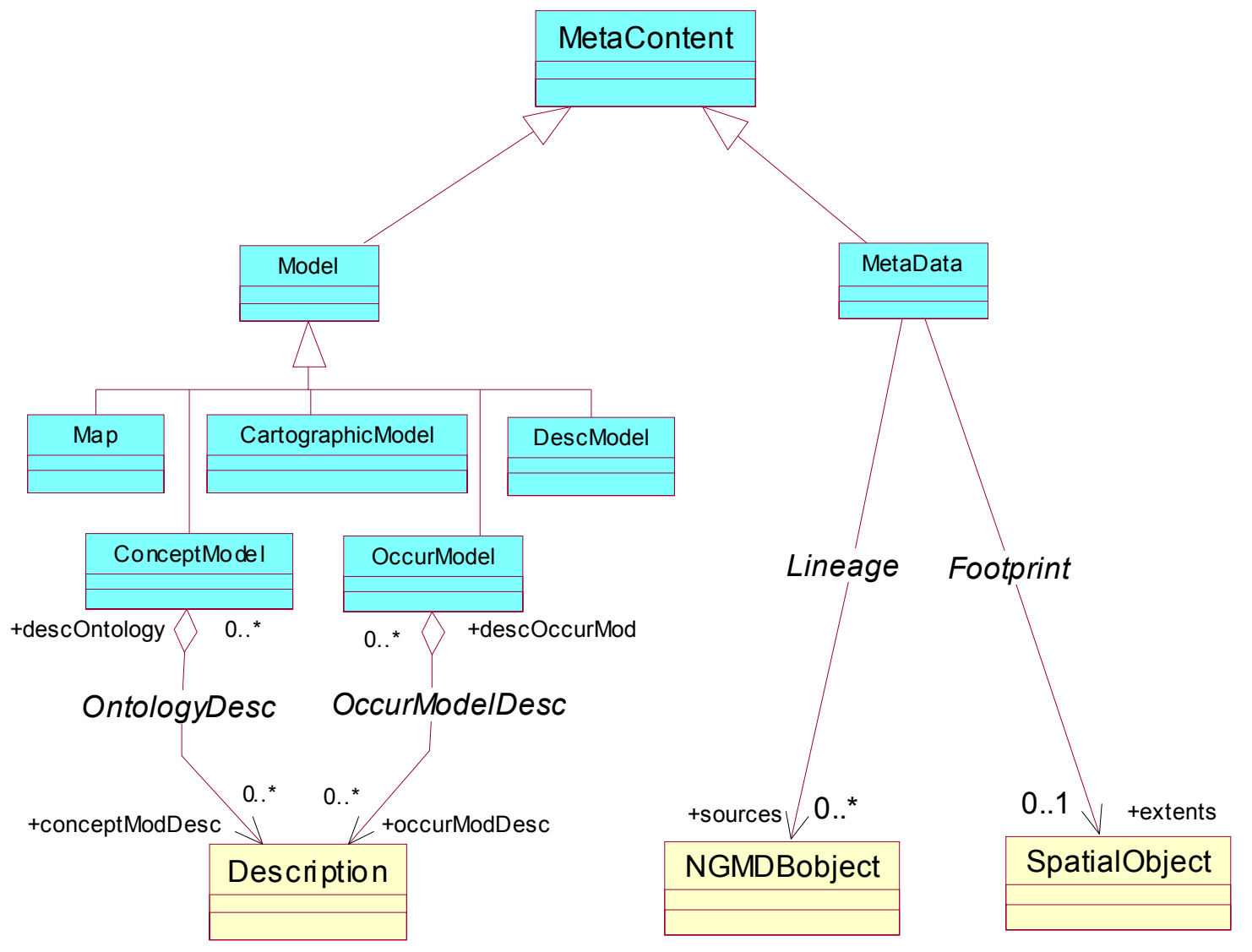

Figure E. Metadata model and metacontent.

\begin{tabular}{|c|}
\hline Key \\
\hline Core Objects \\
\hline Descriptions \\
\hline Concepts \\
\hline MetaContent \\
\hline Cartographic Objects \\
\hline
\end{tabular}




\title{
APPENDIX B. Description of elements of the Logical Model.
}

\author{
Hierarchical notation:
}

Category

\section{Class}

ClassText

ClassDerive

ClassFields

ClassFieldText

Subtype

SubtypeText

SubtypeDerive

SubtypeField

SubtypeFieldText

\section{Core Objects}

\section{NGMDBobject}

An abstract class that is the superclass for all non-metadata classes in the NADM data model. Core Objects may be related to each other.

\section{CartographicObject}

The cartographic object defines the symbology to be applied to occurrences and concepts, and also defines a symbol's text description for use in legends.

Derived from NGMDBobject

Private Attributes:

cart_name : String

The name applied to a cartographic object that typically appears in a legend. In most cases, it is the same as the concept name.

cart_label : String

The character symbol for the object, which may appear on the map. For a rock unit, this would be the unit label, such as TKgr.

cart_code : String

An alternative symbolization code for the cart object. In typical GIS this code may be a symbolization attribute of a spatial object.

cart_desc : String

A text description of the cartographic object; that typically appears on a legend. It may be an abbreviated version of a full text description of a concept.

\section{Concept}

The concept object is an abstract class that provides a category for classifying occurrences. Concepts are subtyped into categories such as rock unit, boundary, border, etc. Such subtypes may also for the content for hierarchical pick lists which represent scientific classification schemes: e.g., a list of structural measurement types such as "foliation", "lineation", etc. 
Private Attributes:

con_name : String

The name of the concept (e.g., Dakota Sandstone, Fault, Political Border, etc.) con_desc : String

The text description of the concept

\section{Description}

Description is an abstract class that contains subtypes such as age, lithology, thickness, and other types of descriptive characteristics for concepts and occurrences.

Derived from NGMDBobject

Private Attributes:

desc : String

A text description

\section{Occurrence}

Occurrence is a class that represents an instance of a concept. For example "Mine X", a specific foliation measurement, etc. Occurrences are most typically spatial, in that many of the features considered by the data model possess a spatial description (i.e., are related to a spatial object). Occurrences are differentiated from spatial objects for three reasons: (1) spatial objects are typically provided by a GIS in a class hierarchy; (2) the same spatial object may be interpreted variously, so each occurrence represents one interpretation of a spatial object (e.g., the same geographic area may be mapped differently by individuals); and (3) occurrences need not have spatial properties (e.g., an instance of a report), though in this implementation they tend to do so.

Derived from NGMDBobject

\section{Relation}

Relation attributes a binary relation in which the objects are of the same type: only between concepts, occurrences, descriptions, cartographic objects or relations themselves. Relation and role types can be specified for a relation, as can be proportion, similarity, and sequence attributes.

Derived from NGMDBobject

Private Attributes:

rel_type : RelType

Specified as proportion, similarity, or sequence

rel_role1 : RoleType

rel_role2 : RoleType

rel_proportion : float

The degree that the part forms of the whole, expressed as a percentage

rel_interval : float

Describes the interval between objects in a sequence (e.g., the time or distance between things)

rel_interval_unit : UnitType

The unit for the interval (e.g., days, meters, etc)

rel_direction : String

The direction of a sequence or interval (e.g., above, below, etc.)

rel_similarity : float

The degree of similarity between the related objects expressed as a percentage 


\section{SpatialObject}

A spatial object contains a geometric description of some thing and is normally the top class from some GIS class hierarchy of geometric objects: e.g., GESW's. A spatial object can have one or more occurrences in the model in order to link it to concepts and descriptions.

\section{Descriptions}

\section{BoundDesc}

A specific geologic boundary description

Derived from Description

FaultDesc

Descriptive information for faults

Derived from BoundDesc

Private Attributes:

\section{flt_throw : String}

The throw information for a fault

\section{Fossil}

A fossil occurrence possessing a fossil name and metadata describing it. Fossil occurrences may be related to a specific site name (OccurName) through the Relation object when the site has been assigned a unique name/number/identifier.

Derived from Description

Private Attributes:

\section{fossil_name : String}

The name of the fossil

\section{GeoChronAge}

The Geochron Age Object describes a numerical geochronological age date. Geochron Ages are typically associated with geologic concepts and occurrences, such as rock units and boundaries, respectively.

Derived from Description

Private Attributes:

chron_age : float
The geochronological age date
chron_method : string
Method used to acquire the geochronological age date
chron_err_plus : float
The positive error for the geochronological age date
chron_err_minus : float
The negative error for the geochronological age date

\section{Image}

The image object records details about a specific image including resolution and display size. It is assumed the actual image is not stored in this object, but may be referenced via a URL in its metadata. 
Private Attributes: image_res : String

The resolution of the image (e.g., 400x600) image_size : String

The size of the image selected from (e.g., thumbnail, half-size or full-size)

\section{LithDescription}

Decribes a lithology by specifying a user-defined rock name and selecting the best-matching standard rock classification from the lith_class and lith_form concepts. Additional non-standard attributes for mineralogy, texture, genesis, fabric, and composition also are permitted.

Derived from Description

Private Attributes:

rock_name : string

A free-form text field containing a user assigned rock name

lith_class : LithClass

A standard rock name term selected from the LithClass class

lith_genesis : LithGenesis

A genetic term(s) selected from the LithGenesis class

lith_texture : LithTexture

A textural term(s) selected from the LithTexture class

lith fabric: LithFabric

Fabric term(s) selected from the LithFabric class

lith_composition : LithComposition

Composition term(s) selected from the LithComposition class

lith_form : LithForm

Form or morphology term(s) selected from the LithForm class

lith_desc : string

A free-form text field for any remaining parts of the lith. description.

\section{MetaContent}

Metacontent provides source or contextual information about an object in the data model; for example, author, time, date, etc; or it acts as a repository for various Models (collections of objects) such as

ConceptModel, OccurrenceModel, etc.

Derived from Description

Private Attributes:

meta_comment : string

A comment about the metadata, or about whatever the metadata is describing

\section{OccurName}

Contains the name of an occurrence (e.g., The Province of Ontario, Center County, Lexington Fault, Last Chance Mine, Station Number 312, etc.)

Derived from Description

Private Attributes:

occur_name : string

The name of the occurrence

\section{Rank}

Describes the level of an object within a hierarchical structure 
Private Attributes:

rank_type : RankType

The rank_type attribute receives a RankType object that defines a hierarchical rank (i.e., lithostratigraphic or lithodemic level). It could contain concepts such as formal or informal stratigraphic subdivisions. It could also be used to describe a hierarchical system for other rankings, e.g., for book components such as chapter, section, subsection, paragraph, etc.

\section{StratigraphicAge}

Describes a time-stratigraphic age range. When a single value vs a range is required then the min. and max. ages are identical. Stratigraphic age ranges are most commonly applied to rock units or geologic boundaries.

Derived from Description

Private Attributes:

min_strat_name : StratTimeScale

The minimum time-stratigraphic age: a Stratigraphic Time

Scale object

max_strat_name : StratTimeScale

The maximum time-stratigraphic age: a Stratigraphic Time

Scale object

\section{StrucMeasure}

Describes a structural measurement by indicating the trend and plunge for linear data and the strike/dip_direction and dip for planar data. A type of structural measurement can also be specified, and the measurement may be related to a specific site name.

Derived from Description

Private Attributes:

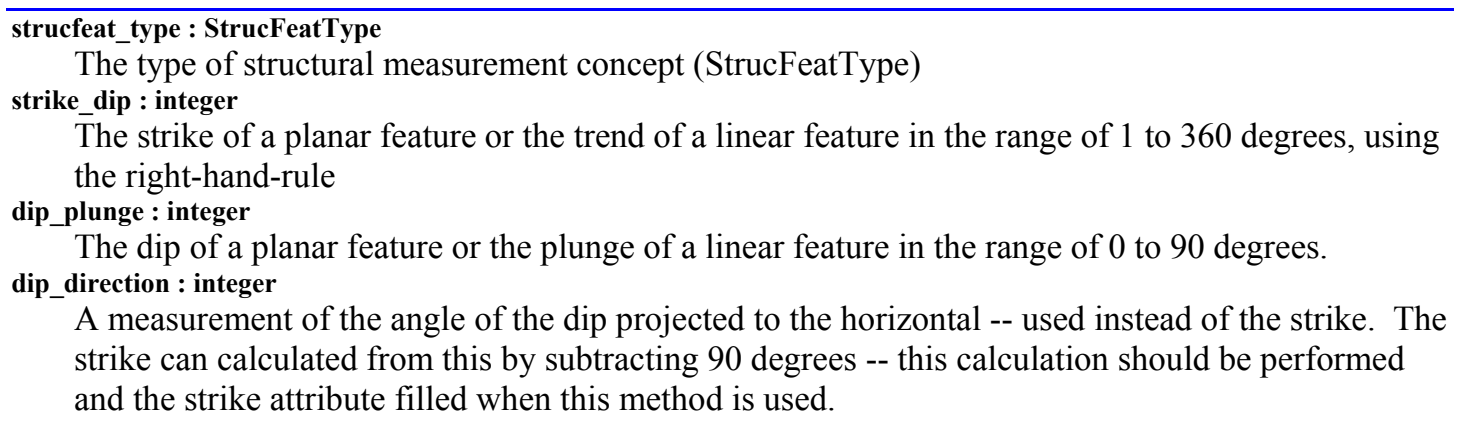

\section{SurfaceDesc}

A specific surface (isopleth) description

Derived from Description

Private Attributes:

surface_parameter: Surface
The name of a surface isopleth concept
surface_value: float
The numeric value for an isopleth occurrence
surface_units: string


The units of measure for the isopleth occurrence

\section{Text}

The text object contains a body of text that may be related to other descriptions, concepts or occurrences. It may also be linked to various documents through the metadata.

Derived from Description

Private Attributes:

text_rank: Rank

The rank of the text (e.g., volume, chapter, section, subsection, caption, abstract) text_body : string

The body of the text. May be empty or possess the text body. If empty, the object may instead use the metadata's URL capability to point to a body of text.

\section{Thickness}

Describes the average or most pertinent thickness of a geologic rock unit, in meters

Derived from Description

Private Attributes:

min thick : float

Min. thickness of the rock unit

max_thick : float

Max. thickness of the rock unit

typ_thick : float

Typical thickness of the rock unit

thick unit: UnitType

Units for the thickness measurement

\section{Concepts}

\section{AccuracyType}

A type of qualitative accuracy category (e.g., interpreted, approximate, high, low, etc.)

Derived from Concept

\section{Border}

Types of non-geologic boundaries (e.g., NEATLINE, LAKE, COUNTY, etc.)

Derived from Concept

\section{Boundary}

Types of geologic boundaries (e.g., Fault, Contact, etc.)

Derived from Concept

Private Attributes:

bnd_modifier : String

Identifies subtypes of a particular kind of geologic boundary (e.g., "dextral" fault).

\section{LithClass}

Each LithClass object is a type of lithology. LithClasses can be organized hierarchically to represent a lithologic classification scheme (i.e., an ontology). 
Private Attributes:

lith_rank : Rank

A Rank object representing the hierarchical level of the lithologic term.

\section{LithComposition}

Contains compositional terms for lithologic descriptions.

Derived from Concept

\section{LithFabric}

Contains fabric terms for lithologic descriptions.

Derived from Concept

\section{LithForm}

Contains form or morphology terms for lithologic descriptions.

Derived from Concept

\section{LithGenesis}

Contains genesis terms for lithologic descriptions.

Derived from Concept

\section{LithTexture}

Contains textural terms for lithologic descriptions.

Derived from Concept

\section{RankType}

The RankType object provides a name and numeric value for a specific level of a hierarchical classification scheme (i.e., ontology or pick list). Examples of ranks include levels in a time scale such as Epoch, or types of formal rock units such as Group, Formation, Member, etc. Not all ranks are named; some may just have numeric values such as levels in a lithologic classification.

Derived from Concept, Description

Private Attributes:

rank_level : Integer

A number assigned to a specific level in a hierarchy (e.g., to a Epoch, Period, Formation, Member, etc.)

\section{RelationType}

A term used to describe the relationship between core objects (i.e., concepts, occurrences, descriptions, and relations).

Derived from Concept

\section{RockUnit}

The Rock Unit class contains the names and definitions of specific rock (map) units (e.g., Dakota Sandstone, Blue Gem coal bed, etc.) 


\section{RoleType}

A term used to describe the role an object plays in the relationship (e.g., in a relationship between a Map object and a Person object, the role of the person might be "author").

Derived from Concept

\section{StratTimeScale}

The StratTimeScale object contains the name and numeric ages for a defined geologic time interval. A hierarchical collection of some StratTimeScale objects (i.e., an ontology/pick list) defines a particular time scale.

Derived from Concept

Private Attributes:

\section{strat_rank : Rank}

A keyword representing the rank of the time-stratigraphic term (e.g., era, epoch, period). These

keywords must be an existing Rank object (i.e., an instance of the Rank concept class).

min_strat_age : Float

Minimum numerical age, in millions of years.

max_strat_age : Float

Maximum numerical age, in millions of years.

\section{StrucFeatType}

The StrucFeatType object represents a type of structural feature (e.g., foliation, lineation, etc.). Note that actual structural measurements are recorded in a StrucMeasure description object.

Derived from Concept

Private Attributes:

struc_rank: Rank

A rank value representing the hierarchical level of the structural measurement term. For example, "Planar" may exist at the first level of a structural hierarchy and "foliation" at a second level.

\section{Surface}

The surface object contains the name of a type of isopleth (e.g., isopach, structure contour, etc.).

Derived from Concept

\section{UnitType}

A unit of measurement (e.g., foot, meter, day, week, year, etc.). This class could be subtyped to represent different categories of measurement units.

Derived from Concept

\section{MetaContent}

\section{MetaData}

Metadata provides source or contextual information about an object in the data model (e.g., author, time, date, title, etc.).

Derived from MetaContent 
Private Attributes:

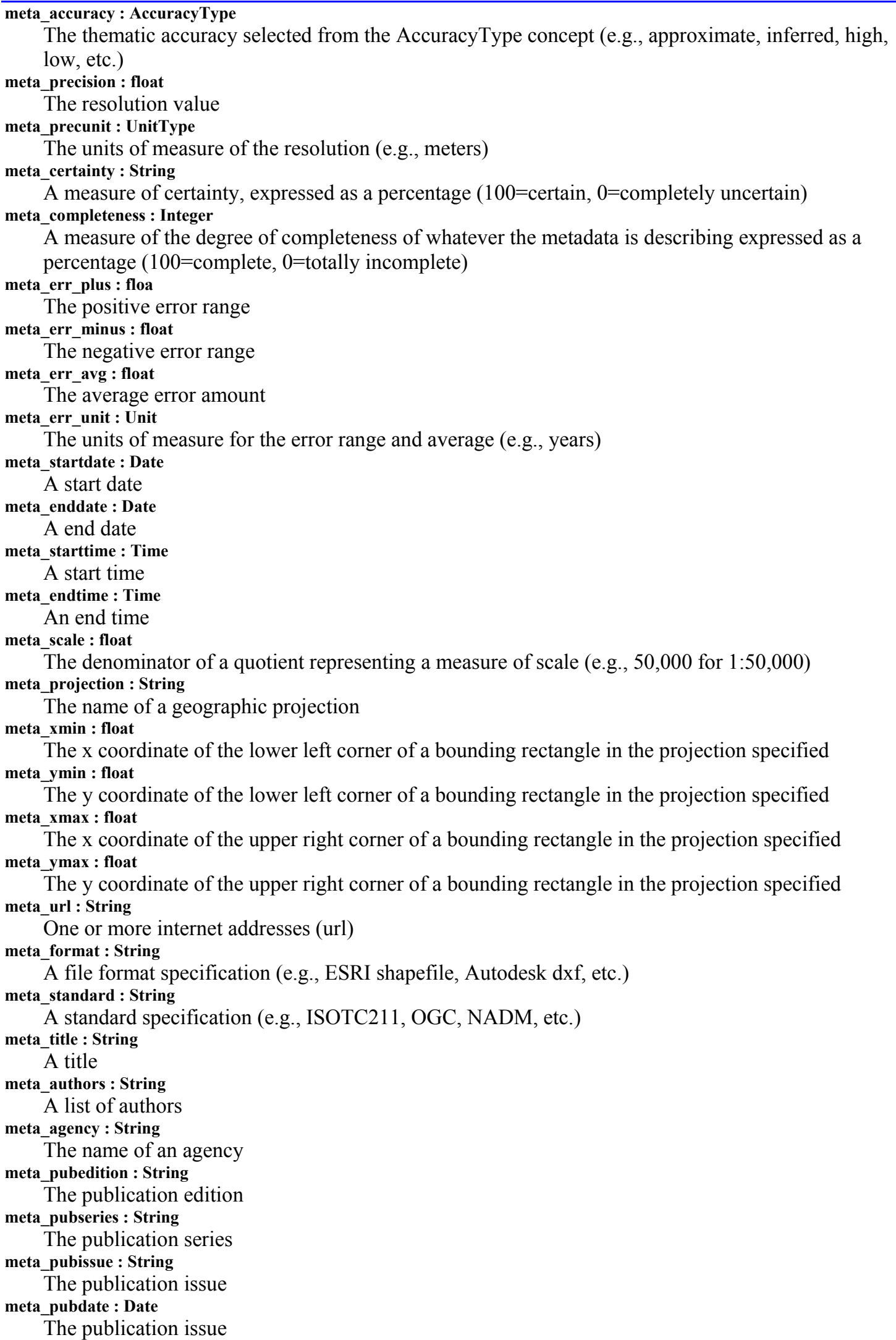


The Central KY Prototype: An object-oriented geologic map data model for the National Geologic Map Database

meta_pubcontact : String

The publication contact

\section{Model}

Model is an abstract class containing the various types of models. Models consist of collections of objects (concepts, occurrences, descriptions, and symbols) and their relations.

Derived from MetaContent

\section{Models}

\section{CartographicModel}

CartographicModel is an abstract class used to define a collection of cartographic objects (symbols and colors) and their relations.

Derived from Model

\section{Legend}

A legend is a collection of hierarchically ordered concepts, their relations and cartographic objects.

Derived from CartographicModel

\section{Palette}

Palette is an abstract class used to denote a collection of cartographic symbol objects.

Derived from CartographicModel

\section{ColorPalette}

A color palette is a named collection of color styles (e.g., USGS standard color library).

Derived from Palette

\section{SymbolPalette}

A symbol palette is a named collection of feature symbols (e.g., USGS standard symbol library).

Derived from Palette

\section{ConceptModel}

A ConceptModel (ontology) is a collection of concepts and their relations; it may be viewed as a particular classification scheme (a specific arrangement of concepts such as rock units or lithologies). For example, a collection of concepts may possess semantic relations (Member X is correlated with Member Y), parent relations (Member $\mathrm{X}$ is part of Formation $\mathrm{A}$ ) and sequential relations (Member $\mathrm{X}$ is younger than Member $\mathrm{Z}$, which is also in Formation A, and above Member Z).

Derived from Model

\section{DescModel}

A DescModel is a collection of descriptions and their relations: i.e., a database, or a table with ordered tuples (rows).

Derived from Model 


\section{Gazetteer}

A Gazetteer is a collection of occurrence (place) names and their relations (e.g., "State College" is part of "Center County" is part of "PA" is part of "USA").

Derived from DescModel

\section{ImageGallery}

An ImageGallery is a collection of images and their relations.

Derived from DescModel

\section{Document}

A Document is a collection of text fragments and their relations: e.g., a book is a collection of text arranged hierarchically (chapter, section, paragraph) and sequentially (chapter 1, 2, 3; section 1.1, 1.2, 1.3; paragraph 1.1.1, 1.1.2, etc.)

Derived from DescModel

\section{SpatialDataset}

A SpatialDataset is collection of spatial objects and their relations

Derived from DescModel

\section{Map}

A Map is a collection of 1) one legend, 2) one or more spatial datasets, 3) one or more description datasets, and 4) other data components such as images (location maps, cross-sections, facies relation diagrams) or text (e.g., map surrounds). In a properly constructed map model, the legend, spatial and descriptive data sets must all intersect - they must share concepts, cartographic objects, spatial objects and descriptions.

Derived from Model

\section{OccurModel}

An OccurModel is a collection of occurrences and their relations.

Derived from Model

\section{Cartographic Objects}

\section{Color}

The color class is an abstract class containing defined standard color schemes (e.g., Pantone, CMYK, RGB). Other color schemes could be defined.

Derived from CartographicObject

\section{CMYK}

A CMYK color value

Derived from Color

Private Attributes:

color_C : Integer

The Cyan color value from CMYK

color_M : Integer

The Magenta color value from CMYK

color_Y : Integer

The Yellow color value from CMYK 
color_K : Integer

The K-black color value from CMYK

\section{Pantone}

A Pantone color value.

Derived from Color

Private Attributes:

color_pantone : Integer
A Pantone color value

\section{RGB}

An RGB color value

Derived from Color

Private Attributes:

color_R : Integer
The Red color value for an RGB color
color_G : Integer
The Green color value for an RGB color
color_B : Integer
The Blue color value for an RGB color

\section{Symbol}

The symbol class defines a specific cartographic symbol. The symbol may be a font, pattern or fill color, and may be used for symbolizing points, lines, polygons, volumes, etc.

Derived from CartographicObject

Private Attributes:

sym_name : String
The name of the symbol
sym_code : Integer
The numeric id of the symbol
sym_desc : String
A text description of the symbol




\section{APPENDIX C. Example map unit description-central Kentucky prototype model.}

The example below was prepared as part of the documentation effort for the overall NADM model design effort to highlight similarities and differences among various implementations of conceptual and logical models. The following tables show how a typical (or atypical) map unit description would be treated in the central Kentucky object-oriented data model. It is based on a legend description extracted from:

Drewes, Harald, 1998, Geologic map of the Bartlett Mountain quadrangle, Pima and Santa Cruz Counties, Arizona: U.S. Geological Survey, Miscellaneous Geologic Investigations Map I-2624, scale $1: 24000$.

Dacitic Vent Breccia (Miocene) - Light-medium-gray, finely porphyritic dacitic rock containing inclusions of Jurassic or Proterozoic granite and Jurassic rhyolite (welded tuff?) as much as $20 \mathrm{~m}$ in diameter. The subcircular outcrop mass of breccia probably is a volcanic vent or throat. A halo of strongly saussuritized rock $0.3-0.5 \mathrm{~km}$ wide (delineated on map) surrounds this vent. The dacitic matrix consists of phenocrysts (25-35\%, as much as $2 \mathrm{~mm}$ in length) set in a cryptocrystalline granular groundmass. Phenocrysts included albitized(?) plagioclase (12$18 \%)$, chloritized biotite (2-5\%), uralized amphibole (2-10\%), magnetite (trace to 2\%), and apatite (trace). Quartz is present as a secondary mineral, filling vugs.

*Magenta highlights in above paragraph not yet treated in conceptual model

*Blue items (below) not yet implemented in logical model implementation

Metadata
\begin{tabular}{|l|l|}
\hline Map.metadata.meta_agency & USGS \\
\hline Map.metadata.meta_authors & Drewes \\
\hline Map.metadata.meta_pubdate & 1998 \\
\hline Map.metadata.meta_pubissue & I-2624 \\
\hline Map.metadata.meta_title & $\begin{array}{l}\text { Geologic map of the Bartlett } \\
\text { Mountain Quadrangle, Pima } \\
\text { \& Santa Cruz counties, AZ }\end{array}$ \\
\hline
\end{tabular}

\section{CartographicObjects}

\begin{tabular}{|l|l|}
\hline CartographicObject.cart_label & Mdv (example) \\
\hline CartographicObject.cart_name & Dacitic Vent Breccia \\
\hline CartographicObject.cart_id & 100001 (example) \\
\hline
\end{tabular}

\section{Symbol}

\begin{tabular}{|l|l|}
\hline CartographicObject.cart_id & 100001 \\
\hline CMYK.color_C & 56 \\
\hline CMYK.color_M & 0 \\
\hline CMYK.color_Y & 47 \\
\hline CMYK.color_K & 34 \\
\hline
\end{tabular}




Concepts
\begin{tabular}{|l|l|}
\hline RockUnit.con_name & Dacitic Vent Breccia \\
\hline StratTimeScale.con_name & Miocene \\
\hline StratTimeScale.con_name & Proterozoic \\
\hline StratTimeScale.con_name & Jurassic \\
\hline Lith_Class.con_name & Aphanitic.Felsic.Dacite \\
\hline Lith_Class.con_name & Phaneritic.Felsic.Granite \\
\hline Lith_Class.con_name & Aphanitic.Felsic.Rhyolite \\
\hline Lith_Texture.con_name & porphyritic \\
\hline Llith_Fabric.con_name & brecciated \\
\hline Mineral.con_name & plagioclase \\
\hline Mineral.con_name & biotite \\
\hline Mineral.con_name & amphibole \\
\hline Mineral.con_name & magnetite \\
\hline Mineral.con_name & apatite \\
\hline Mineral.con_name & quartz \\
\hline Matrix.con_name & groundmass \\
\hline etc._-for remaining blue items & \\
\hline
\end{tabular}

\section{Descriptions (for Dacitic Vent Breccia)}

StratigraphicAge

\begin{tabular}{|l|l|}
\hline StratigraphicAge.max_strat_name & Miocene \\
\hline StratigraphicAge.min_strat_name & Miocene \\
\hline
\end{tabular}

LithDescription (Dacite)

\begin{tabular}{|l|l|}
\hline LithDescription.rock_name & Dacite \\
\hline LithDescription.lith_class & Aphanitic.Felsic.Dacite \\
\hline LithDescription.lith_texture & porphyritic \\
\hline LithDescription.lith_fabric & brecciated \\
\hline LithDescription.lith_color & light gray \\
\hline LithDescription.lith_color & medium grey \\
\hline
\end{tabular}

LithDescription (Granite)

\begin{tabular}{|l|l|}
\hline LithDescription.rock_name & Granite \\
\hline LithDescription.lith_class & Phaneritic.Felsic.Granite \\
\hline LithDescription.max_size & 20 \\
\hline LithDescription.size_unit & meters \\
\hline LithDescription.lith_habit & inclusion \\
\hline StratigraphicAge.max_strat_name & Proterozic \\
\hline StratigraphicAge.min_strat_nam & Jurassic \\
\hline StratigraphicAge.metaData.meta_certainty & low \\
\hline
\end{tabular}

\section{LithDescription (Rhyolite)}

\begin{tabular}{|l|l|}
\hline LithDescription.rock_name & rhyolite \\
\hline LithDescription.lith_class & Aphanitic.Felsic.Rhyolite \\
\hline LithDescription.lith_genesis & welded tuff \\
\hline LithDescription.max_size & 20 \\
\hline LithDescription.size_unit & meters \\
\hline LithDescription.lith_habit & inclusion \\
\hline LithDescription.meta_certainty & low \\
\hline StratigraphicAge.max_strat_name & Jurassic \\
\hline StratigraphicAge.min_strat_name & Jurassic \\
\hline
\end{tabular}


LithComponent (Plagioclase)

\begin{tabular}{|l|l|}
\hline LithComponent.component_name & plagioclase \\
\hline LithComponent.min_percent & 12 \\
\hline LithComponent.max_percent & 18 \\
\hline LithComponent.max_size & 2 \\
\hline LithComponent.size_unit & $\mathrm{mm}$ \\
\hline LithComponent.alteration & albitized \\
\hline LithComponent.meta_certainty & low* \\
\hline
\end{tabular}

* Certainty applies to alteration, but model does not support metadata on attribute values

LithComponent (Biotite)

\begin{tabular}{|l|l|}
\hline LithComponent.component_name & biotite \\
\hline LithComponent.min_percent & 2 \\
\hline LithComponent.max_percent & 5 \\
\hline LithComponent.max_size & 2 \\
\hline LithComponent.size_unit & mm \\
\hline LithComponent.alteration & chloritized \\
\hline
\end{tabular}

LithComponent (Amphibole)

\begin{tabular}{|l|l|}
\hline LithComponent.component_name & amphibole \\
\hline LithComponent.min_percent & 2 \\
\hline LithComponent.max_percent & 10 \\
\hline LithComponent.max_size & 2 \\
\hline LithComponent.size_unit & $\mathrm{mm}$ \\
\hline LithComponent.alteration & uralized \\
\hline
\end{tabular}

LithComponent (Magnetite)

\begin{tabular}{|l|l|}
\hline LithComponent.component_name & magnetite \\
\hline LithComponent.min_percent & trace \\
\hline LithComponent.max_percent & 2 \\
\hline LithComponent.max_size & 2 \\
\hline LithComponent.size_unit & $\mathrm{mm}$ \\
\hline
\end{tabular}

LithComponent (Apatite)

\begin{tabular}{|l|l|}
\hline LithComponent.component_name & apatite \\
\hline LithComponent.min_percent & trace \\
\hline LithComponent.max_percent & 2 \\
\hline LithComponent.max_size & 2 \\
\hline LithComponent.size_unit & $\mathrm{mm}$ \\
\hline
\end{tabular}

\section{LithComponent (Quartz)}

\begin{tabular}{|l|l|}
\hline LithComponent.component_name & quartz \\
\hline LithComponent.component_habit & vug filling \\
\hline
\end{tabular}

LithComponent (Groundmass)

\begin{tabular}{|l|l|}
\hline LithComponent.component_name & groundmass \\
\hline LithComponent.max_size & cryptocrystalline \\
\hline LithComponent.size_unit & relative \\
\hline LithComponent.component_texture & granular \\
\hline
\end{tabular}


The Central KY Prototype: An object-oriented geologic map data model for the National Geologic Map Database

\section{Relations}

(LithComponent-LithDescription)

\begin{tabular}{|l|l|l|l|l|}
\hline Relation(Child) & rel_role1 & rel_type & rel_role2 & Relation(Parent) \\
\hline LithComponent(Plagioclase) & mineral & IsPartof & lithology & LithDescription (Dacite) \\
\hline LithComponent(Biotite) & mineral & IsPartof & lithology & LithDescription (Dacite) \\
\hline LithComponent(Amphibole) & mineral & IsPartof & lithology & LithDescription (Dacite) \\
\hline LithComponent(Magnitite) & mineral & IsPartof & lithology & LithDescription (Dacite) \\
\hline LithComponent(Apatite) & mineral & IsPartof & lithology & LithDescription (Dacite) \\
\hline LithComponent(Quartz) & mineral & IsPartof & lithology & LithDescription (Dacite) \\
\hline LithComponent(Groundmass) & matrix & IsPartof & lithology & LithDescription (Dacite) \\
\hline
\end{tabular}

